\title{
RANCANG BANGUN MESIN PENGGORENG KERUPUK UPIL
}

\author{
Dofpi Kristanto \\ Teknik Mesin, Fakultas Teknik \\ Universitas Maarif Hasyim Latif, Sidoarjo, Indonesia \\ e-mail : dofpi-kristanto@student.umaha.ac.id
}

\begin{abstract}
ABSTRAK
Krupuk upil merupakan salah satu jenis makanan ringan yang proses penggorengannya menggunakan pasir. Dari hasil observasi dalam 1 hari Proses Penggorengan krupuk upil para pekerja hanya mampu menghasilkan $80 \mathrm{~kg}$ kerupuk, sementara tingkat permintaan pasar melebihi jumlah tersebut. Proses terpenting pada Penggorengan adalah membutuhkan waktu yang cepat, serta efektif kami merancang suatu alat Penggoreng Kerupuk Upil Dengan Screw Dilengkapi Pembalik Putaran dengan system pengaduk screw yang bisa berputar kanan maupun kiri sesuai durasi waktu yang bisa ditentukan sendiri oleh timer off inverter dengan tambahan plat berlubang untuk memisahkan antara pasir dengan kerupuk ketika keluar dari Drum Penggorengan Guna mempercepat waktu penggorengan. Dari hasil penelitian untuk 500 gram kerupuk upil didapatkan waktu ideal penggorengan 50 detik dengan Suhu $200^{\circ} \mathrm{C}$, Pasir yang ideal untuk mengoreng kerupuk pada suhu $200^{\circ} \mathrm{C}$ dengan diameter 1-2 mm, Suhu ideal untuk penggorengan kerupuk pasir minimal $170{ }^{\circ} \mathrm{C}$ dengan waktu penggorengan sedikit lama mencapai 80 detik, Suhu maximal yang paling idal $\pm 200 \stackrel{\circ}{\mathrm{C}}$
\end{abstract}

Kata kunci: kerupuk upil, drum pengoreng, screw, dan inverter.

\section{PENDAHULUAN}

Kerupuk upil merupakan salah satu jenis makanan ringan yang proses penggorengannya menggunakan pasir, makanan ini akrab dengan lidah masyarakat indonesia dikarenakan mempunyai rasa yang berbeda apabila digoreng dengan minyak. Bahkan, risiko untuk melempem dapat ditekan karena dapat didaur ulang kelebihan lain kerupuk upil adalah bebas kolesterol dan baik untuk dikonsumsi setiap hari.

Kerupuk upil merupakan penghasilan utama mayoritas penduduk di desa gampang kecamatan prambon kabupaten sidoarjo kerupuk upil merupakan penghasilan utama mayoritas penduduk di desa gampang kecamatan prambon kabupaten sidoarjo salah satu ukm pengoreng kerupuk upil. Proses penggorengan masih dilakukan secara manual dan ukuran tempat menggorengnya kecil. Selain itu, kekurangan dari alat ini yaitu masih menggunakan tongkat pengaduk dari kayu untuk meratakan dan mengeluarkan kerupuknya masih terdapat pasir yang ikut terbawa keluar sehingga dibutuhkan kerja 2 kali untuk memisahkan kerupuk dari pasirnya dengan pengayak.

Dalam 1 hari proses penggorengan kerupuk upil para pekerja hanya mampu menghasilkan $80 \mathrm{~kg}$ kerupuk, sementara tingkat permintaan pasar melebihi jumlah tersebut. Proses terpenting pada penggorengan adalah membutuhkan waktu yang cepat, serta efektif kami merancang suatu alat penggoreng kerupuk upil dengan screw dilengkapi pembalik putaran dengan system pengaduk screw yang bisa berputar kanan maupun kiri sesuai durasi waktu yang bisa ditentukan sendiri oleh timer off dengan tambahan plat berlubang untuk memisahkan antara pasir dengan kerupuk ketika keluar dari drum penggorengan guna mempercepat waktu penggorengan.

Tujuan dari pembahasan penelitian ini adalah:

1. Untuk mengetahui waktu yang paling optimal pada proses penggorengan sesuai kapasitas bahan baku yang digoreng.

2. Untuk mengetahui putaran yang paling optimal pada proses penggorengan sesuai kapasitas bahan baku yang digoreng

Langkah-langkah proses penggorengan kerupuk upil secara manual dan sederhana;

1. Mempersiapkan peralatan menggoreng kerupuk upil meliputi : kompor, wajan serta pasirnya, peniris, pengaduk dan pasir sebagai media pengganti minyak goring

2. Panaskan pasir diatas wajan selama 20 menit hingga kadar airnya menguap dan kering hingga suhunya kurang lebih 200 derajat celcius

3. Masukan kerupuk mentah yang sudah dijemur kedalam wajan yang berisikan pasir panas 
4. Aduk dan ratakan kerupuk mentah dengan pasir panas agar matangnya merata dan mengembang sempurna.

5. Bila sudah mengembang sempurna angkat kerupuk dengan peniris dan goyang-goyangkan agar pasirnya turun kembali kewajan

\section{Drum penggoreng kerupuk}

Tempat untuk menggoreng kerupuk dengan media pasir panas dibutuhkan drum dari stainless steel sebagai tempat penggorenganya, pada dasarnya menerapkan rumus keliling lingkaran yang ukuranya ditentukan sesuai kapasitas penggorengan bahan baku kerupuk.

\section{METODE PENELITIAN}

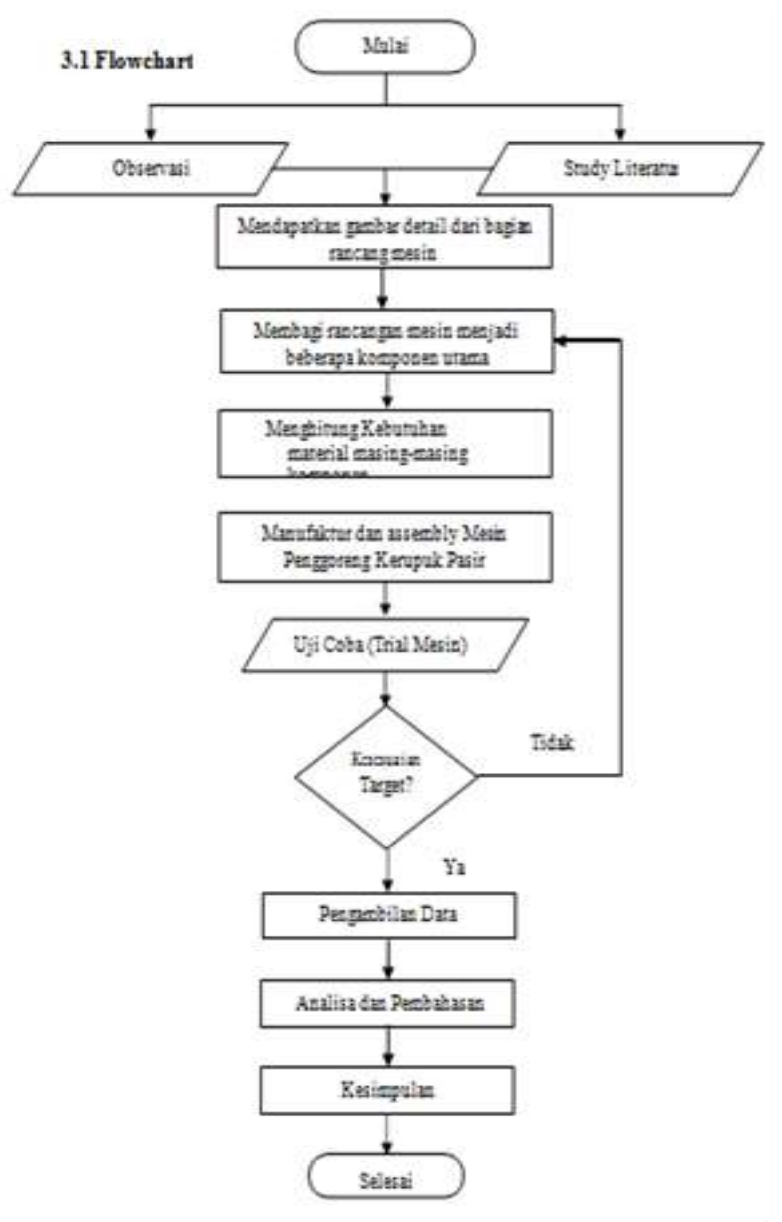

Gambar 1. Alur Penelitian

\section{Proses Pembuatan Mesin}

Setelah kebutuhan alat dan bahan terlengkapi, tahap selanjutnya dalam langkah penelitian ini adalah proses pembuatan alat. Pada proses pembuatan mesin penggoreng kerupuk upil ini terbagi menjadi 3 bagian, yaitu :

a. Pembuatan part-part untuk Alat Penggoreng kerupuk upil.

b. Pembuatan Komponen Pendukung.

c. Proses Assembly.
Pembuatan mesin meliputi pembuatan unit-unit yang ada, pembuatan dilakukan melalui proses yang tepat. Proses yang akan banyak dilakukan ialah proses pemotongan, pembengkokan, pengerolan dan pengelasan bahan. Komponen yang digunakan pada alat ini tidak semua dibuat secara custom, namun ada beberapa komponen yang sesuai spesifikasi penelitian yang langsung bisa didapatkan di pasaran. selanjutnya alat di uji coba. Cara penggunaan mesin penggoreng kerupuk upil dengan pasir

1. Persiapkan bahan kerupuk yang akan digoreng pastikan dalam keadaan kering dan sudah di jemur

2. Pastikan gas LPG sudah dipasang di regulator dan dalam keadaan masih penuh periksa apabila terjadi kebocoran gas, jika terdapat kebocoran pada regulator gas IPG segera ganti seal tabung gas dengan yang masih baru dan baik

3. Persiapkan alat bantu penggoreng seperti korek api sebagai pemicu kompor dan wadah kerupuk matang, wadah penampung pasir

4. Setelah bahan dan alat sudah siap buka valve regulator lpg secara sedikit dan nyalakan 2 tungku api berbahan bakar lpg dengan korek api agar memanaskan pasir dalam drum

5. Setelah api menyala besarkan valve pada regulator gas agar api lebih merata memanaskan pasir dalam drum

6. Kemudian hubungkan colokan listrik ke stop kontak sebagai daya pemutar motor drum, kemudian arahkan tuas kem starter ke posisi I untuk proses memasak

7. Setelah dirasa cukup panas kira-kira 10-15 menit pemanasancek suhu dengan laser gun thermometer pastikan suhu sudah mencapai 180 derajat Celcius maka kerupuk siap dimasukan untuk proses penggorengan

8. Apabila suhu belum mencapai 180 Derajat Celcius makan besarkan lagi valve regulator lpg agar api pada kompor besar bertujuan untuk menaikan suhu panas sesuai kebutuhan

9. Setelah suhu stabil maka masukan kerupuk ke dalam drum rotary yang berputar kearah dalam (I) dengan kapasitas sekali proses $0,5 \mathrm{~kg}$

10. Hitung waktu penggorengan kerupuk dengan durasi 55-70 detik. Setelah menggembang sempurna posisikan tuas kem starter ke posisi 0 kemudian pindahkan ke posisi II untuk proses pengeluaran kerupuk

11. Kerupuk yang sudah matang dan menggembang sempurna akan terdorong keluar oleh screw yang arah putaranya terbalik dari proses penggorenganya

12. Kerupuk yang sudah matang akan terpisah dengan pasirnya oleh plat penyaring dan jatuh ke wadah kerupuk 
13. Pasir juga akan terpisah ke wadah pasir agar nantinya dapat dipakai proses penggorengan lagi dalam drum

14. Setelah proses selesai matikan kompor dengan menuturp aliran gas dari valve regulator hingga api padam

15. Setelah api padam matikan motor penggerak dengan menggeser cam starter ke posisi 0

16. Setelah berhenti cabut aliran listrik dari stop kontak dan lepaskan regulator LPG dari tabungnya

17. Kemudian simpanlah peralatan penggoreng agar tidak mengganggu.

18. Masukan krupuk yang sudah di goreng hingga mekar ke dalam plastik kedap udara agar tidak melempem

19. Kemudian simpanlah peralatan penggorengan agar tidak menggangu

20. Proses penggorengan selesai kerupuk siap di jual

\section{HASIL DAN PEMBAHASAN}

\section{Perhitungan Berat Drum dan screw}

\section{Penentuan Volume Tabung Penggoreng}

1. Dari hasil Percobaan 2 jenis ukuran kerupuk :

a. Diameter kerupuk sebelum di goreng $8 \mathrm{~cm}$ setelah digoreng menjadi diameter $8,5 \mathrm{~cm}$

b. Diameter kerupuk sebelum di goreng $5 \mathrm{~cm}$ setelah digoreng menjadi diameter $5,5 \mathrm{~cm}$

2. Volume penggorengan ideal adalah maksimal $1 / 3$ volume tabung untuk hasil lebih optimal kematangan kerupuk, pasir tidak tumpah keluar,dan berat kerupuk mencapai 4 ons.

Menghitung luasan dan berat Drum luar Dengan rumus lingkaran

a. Luas Tutup Belakang dengan bahan plat besi

$=3.14 / 4 \times 772 \mathrm{~cm}$

$=4654,26 \mathrm{~cm} 2$

Berat Plat

$=4,7 \mathrm{~m} \times 0.0010 \mathrm{~m} \times 0,8 \mathrm{~m} \times 7850 \mathrm{~kg} / \mathrm{m} 3$ $=28 \mathrm{~kg}$

b. Selimut tabung Luar

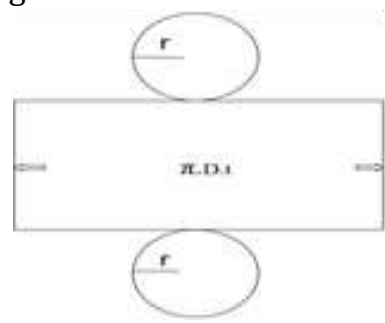

Gambar 2 Selimut Tabung

Luas Selimut Tabung

$=\pi$.D.t

$$
\begin{aligned}
& =3.14 \times 0,77 \mathrm{~m} \times 0,8 \mathrm{~m} \\
& =1,9 \mathrm{~m} 2 \\
& \text { Berat Plat } \\
& =1,9 \mathrm{~m} 2 \times 0,0010 \mathrm{~m} \times 7850 \mathrm{~kg} / \mathrm{m} 3 \\
& =12 \mathrm{~kg}
\end{aligned}
$$

\section{Menghitung luasan dan berat Drum luar Dengan} rumus lingkaran

a. Selimut tabung dalam dengan bahan Stainless steel tipe 304

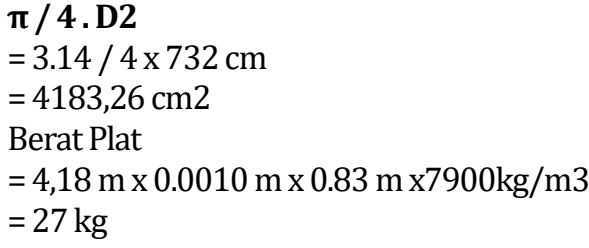

b. Luasan dan berat plat Screw berbentuk lingkaran dengan Stainless steel tipe 304

$((\mathrm{phi}) \pi / 4 . \mathrm{D} 2)-((\mathrm{phi}) \pi / 4 . \mathrm{D} 2)$

$=(0.785 \times 0.533)-(0.785 \times 0.185)$

$=0.434105 \mathrm{~m} 2-0.145225 \mathrm{~m} 2$

$=0.28888 \mathrm{~m} 2$

Berat Plat $=0.29 \mathrm{~m} 2 \times 0.0010 \mathrm{~m} \times 7900 \mathrm{~kg} / \mathrm{m} 3$ $=2.3 \mathrm{~kg} \times 3$

$=7 \mathrm{~kg}$

c. Luasan dan berat plat penyanga drum berbentuk lingkaran

(phi) $\pi / 4$. D2 $. \mathrm{t}=0.785 \times 0.030 \mathrm{~m} \times 0.05 \mathrm{~m}$

$=0.785 \times 0.0090 \mathrm{~m} \times 0.05 \mathrm{~m} \times 7900 \mathrm{~kg} / \mathrm{m} 3$

$=2.7 \mathrm{~kg}$

Perhitungan kebutuhan Torsi motor dengan menghitung berat Drum

a. Berat Drum $=28 \mathrm{~kg}+12 \mathrm{~kg}+27 \mathrm{~kg}+7 \mathrm{~kg}+2.7 \mathrm{~kg}$ $=76.7 \mathrm{~kg}$

b. BeratPasir $=20 \mathrm{~kg}$

c. Berat total = Berat Drum + Berat Pasir $=96.7 \mathrm{~kg}$

d. Rumus mencari torsi yang Digunakan

$$
\begin{aligned}
\mathrm{f}(\text { total }) & =\mathrm{f} 1+\mathrm{f} 2 \\
& =76,7 \mathrm{Kg}+20 \mathrm{Kg} \\
& =96,7 \mathrm{Kg} \\
\mathrm{T} & =\mathrm{f}_{\text {(Total). }} \mathrm{r} \\
& =(96.7 \mathrm{~kg} \times 9,8 \mathrm{~m} / \mathrm{s} \times 0,38 \mathrm{~m}) \\
& =360 \mathrm{Nm}
\end{aligned}
$$

e. Rasio Gearbox yang dipakai $=15: 1$

$$
\text { Mencari Daya }
$$

$\mathrm{T}=360 \mathrm{Nm} / 15=24 \mathrm{Nm}$

$$
\mathrm{T}=716200 \mathrm{~N} / \mathrm{n}: 9,8 \mathrm{~m} / \mathrm{s}
$$$$
\mathrm{N}=0,49 \mathrm{HP}
$$

$$
N=\frac{9,8 \frac{\mathrm{m}}{\mathrm{s}} \times 1500 \times 24 \mathrm{Nm}}{716200}
$$

Perhitungan Torsi Motor

Daya Yang Digunakan $1 \mathrm{Hp}$

$$
\mathrm{T}=\frac{716200 \mathrm{~N}}{n}
$$




$$
\begin{aligned}
& =\frac{7162001}{1500} \\
& =\frac{477 \mathrm{Kgf}}{9,8 \mathrm{~m} / \mathrm{s}} \\
& =48 \mathrm{Nm}
\end{aligned}
$$

Perhitungan Rasio Gearbox

$$
\text { ratio }=\frac{\mathrm{n} 1}{n 2}
$$

Jika Putaran yang di inginkan adalah 100 Rpm maka

$$
\frac{1500 \mathrm{rpm}}{100 \mathrm{rpm}}=15 \text { ratio }
$$

Perhitungan Rasio Sprocket

$$
\frac{\mathrm{n} 1}{n 2}=\frac{d 2}{d 1}
$$

Untuk menurunkan rpm sesuai dengan rpm drum yang di inginkan

$$
\frac{100 \mathrm{rpm}}{40 \mathrm{rpm}}=\frac{15 \mathrm{gigi}}{40 \mathrm{gigi}}
$$

Maka rasio gear sprocket yang dibutuhkan adalah 2,6 Torsi Motor

$$
\begin{aligned}
\mathrm{T} & =\frac{716200 \mathrm{~N}}{n} \\
& =\frac{7162001}{1500} \\
& =\frac{477 \mathrm{Kgf}}{9,8 \mathrm{~m} / \mathrm{s}} \\
& =48 \mathrm{Nm}
\end{aligned}
$$

Rasio Gearbox dan sprocket

$$
\text { Rasio gearbox } \quad=15: 1
$$$$
\text { Rasio Sprocket } \quad=2,6: 1
$$

Torsi motor yang dayanya diteruskan gearbox

$$
\begin{aligned}
\mathrm{T} & =48 \mathrm{Nm} \times 15 \text { Rasio } \\
& =720 \mathrm{Nm}
\end{aligned}
$$

Putaran motor yang direduksi Gearbox

$$
\frac{1500 \mathrm{rpm}}{15 \mathrm{ratio}}=100 \mathrm{rpm}
$$

\begin{tabular}{|c|c|c|c|c|}
\hline $\mathrm{N}_{0}$ & Jumbh Kerupul & $\begin{array}{c}\text { Stha } \\
\text { Peaggoreagun }\end{array}$ & $\begin{array}{c}\text { Walte } \\
\text { Penggorengan }\end{array}$ & $\begin{array}{c}\text { Hasil } \\
\text { Percobaan } \\
\text { Ratarata }\end{array}$ \\
\hline 1 & $50 \mathrm{gram}$ & $170^{\circ} \mathrm{C}$ & 50 detic & Culop Bak \\
\hline 2 & $50 \mathrm{grm}$ & $170^{\circ} \mathrm{C}$ & 80 detil & Sarget Ba \\
\hline 3 & $50 \mathrm{gmen}$ & $170^{2} \mathrm{C}$ & 110 detix & Kurang Ba \\
\hline
\end{tabular}

Torsi gearbox yang dayanya diteruskan sprocket

$$
\begin{aligned}
\mathrm{T} & =48 \mathrm{Nm} \times 17,6 \text { Rasio } \\
& =845 \mathrm{Nm}
\end{aligned}
$$

Putaran gearbox yang direduksi sprocket

$$
\frac{100 \mathrm{rpm}}{2,6 \text { ratio }}=38,5 \mathrm{rpm}
$$

Maka didapatkan putaran 38.5 rpm dengan torsi $845 \mathrm{Nm}$ Torsi yang dibutuhkan untuk memutar drum adalah 360

\begin{tabular}{|c|c|c|c|c|}
\hline $\mathrm{N}_{0}$ & Jamhh Kerapuk & $\begin{array}{c}\text { Suht } \\
\text { Peaggoreagan }\end{array}$ & $\begin{array}{c}\text { Walktu } \\
\text { Peaggorengan }\end{array}$ & $\begin{array}{c}\text { Hasil } \\
\text { Percobaan } \\
\text { Rata-rata }\end{array}$ \\
\hline 1 & $50 \mathrm{gram}$ & $200^{\circ} \mathrm{C}$ & 30 detil & Cukp Baik \\
\hline 2 & 50 gram & $200^{\circ} \mathrm{C}$ & 50 detil & Sangat Baik \\
\hline 3 & $50 \mathrm{gran}$ & $200^{\circ} \mathrm{C}$ & 70 decil & Kurane Bail \\
\hline
\end{tabular}
Nm sedangkan rpm nya adalah 38.5 rpm

\section{Percobaan Penggorengan}

Percobaan penggorengan kerupuk pasir dilakukan pada dua suhu yang berbeda suhu $170{ }^{\circ} \mathrm{C}$ untuk awal start penggunaan setelah sekian kali penggorengan suhu bisa naik mencapai $200^{\circ} \mathrm{C}$.
Tabel 1 Hasil percobaan penggorengan kerupuk (upil) pada Suhu penggorengan $170^{\circ} \mathrm{C}$.

Masing - masing data di uji 5 kali pengujian

Keterangan

Sangat Baik : : kerupuknya kriuk tidak gosong

Cukup baik : : kerupuknya kurang kriuk tidak gosong

Kurang baik : : kerupuknya kriuk sedikit gosong Tabel 2 Hasil percobaan penggorengan kerupuk (upil) pada Suhu penggorengan $200{ }^{\circ} \mathrm{C}$.

Keterangan

Sangat Baik : : kerupuknya kriuk tidak gosong

Cukup baik

: kerupuknya kurang kriuk tidak gosong

Kurang baik : kerupuknya kriuk sedikit gosong

Pada tabel 1 Percobaan penggorengan kerupuk upil ada 3 percobaan masing - masing di uji 5 kali percobaan. Pertama jumlah kerupuk 50 gram digoreng pada suhu $170{ }^{\circ} \mathrm{C}$ dalam waktu 50 detik yang hasilnya cukup bagus (kerupuknya cukup kriuk tidak gosong). Kedua jumlah kerupuk 50 gram digoreng pada suhu 170 ${ }^{0} \mathrm{C}$ dalam waktu 80 detik yang hasilnay sangat bagus (kerupuknya kriuk tidak gosong). Ketiga jumlah kerupuk 50 gram digoreng pada suhu $170{ }^{\circ} \mathrm{C}$ dalam waktu 110 detikyang hasilnya kurang bagus (kerupuknya kriuk tapi sedikit gosong).

Pada tabel 2 Percobaan penggorengan kerupuk upil ada 3 percobaan masing - masing di uji 5 kali percobaan. Pertama jumlah kerupuk 50 gram digoreng pada suhu $200{ }^{\circ} \mathrm{C}$ dalam waktu 30 detik yang hasilnya cukup bagus (kerupuknya cukup kriuk tidak gosong). Kedua jumlah kerupuk 50 gram digoreng pada suhu 200 ${ }^{0} \mathrm{C}$ dalam waktu 50 detik yang hasilnay sangat bagus (kerupuknya kriuk tidak gosong). Ketiga jumlah kerupuk 50 gram digoreng pada suhu $200{ }^{\circ} \mathrm{C}$ dalam waktu 70 detikyang hasilnay kurang bagus (kerupuknya kriuk tapi sedikit gosong).

Dalam percobaan penggorengan kerupuk upil diatas semuanya digoreng menggunakan pasir. Percobaan pertama kerupuk dengan hasilnya cukup bagus, ketika proses pengeluaran ada sedikit pasirnya yang menempel pada kerupuk. Percobaan kedua kerupuk pasir dengan hasilnya sangat bagus, ketika proses pengeluaran tidak ada pasirnya yang menempel 
pada kerupuk. Percobaan ketiga kerupuk hasilnya kurang bagus, ketika proses pengeluaran tidak ada pasir yang menempel pada kerupuk.

Dari semua percobaan pada tabel 4.2 Percobaan dengan hasil yang diinginkan adalah percobaan kedua dengan jumlah kerupuk 50 gram digoreng pada suhu $200{ }^{\circ} \mathrm{C}$ dalam waktu 50 detik yang hasilnya sangat bagus dan kerupuk yang dikeluarkannya tidak ada pasir yang menempel pada kerupuk.

Dari hasil percobaan penggorengan dengan berat kerupuk 50 gram yang digoreng dengan Drum rotary Screw maka suhu waktu ideal untuk kerupuk upil adalah $170 \stackrel{\circ}{\circ}$ pada waktu 80 detik atau $200 \stackrel{\circ}{\circ}$ pada waktu 50 detik, untuk kerupuk dengan berat 500 gram kerupuk (upil) mendapatkan waktu 55 detik pada suhu $200^{\circ} \mathrm{C}$

Pada alat lama penggorengan kerupuk upil dengan berat 500 gram membutuhkan waktu 145 detik, ketika menggunakan alat penggoreng kerupuk pasir dengan screw dilengkapi pembalik putaran membutuhkan waktu 115 detik, maka efisiensi setiap penggorengan kerupuk $10 \mathrm{~kg}$ memiliki efisiensi $300 \%$.

Selain itu alat penggoreng kerupuk pasir dengan screw dilengkapi pembalik putaran lebih efisien dibandingkan alat penggoreng kerupuk secara manual karena cara penggorengannya cukup mudah, tinggal kerupuknya dimasukkan, ditunggu beberapa detik, lalu tekan tombol pembalik putaran, dan kerupuknya keluar sendiri tanpa harus diaduk terlebih dahulu pakai peniris,diratakan biar matang secara merata kemudiandiambil kerupuknya.

Untuk kerupuk yang digoreng dengan alat penggoreng pasir ini tidak mengandung kolestrol jadi lebih sehat dikonsumsi karena digoreng dengan media pasir.

\section{PENUTUP}

\section{Kesimpulan}

Rancang bangun alat penggoreng kerupuk pasir dengan screw dilengkapi pembalik putaran dimensi alat (p) $1850 \mathrm{~mm} \times$ (l) $950 \mathrm{~mm} \times(\mathrm{t}) 1750 \mathrm{~mm}$.

1. Dari hasil percobaan di dapatkan untuk 500 gram kerupuk upil didapatkan waktu ideal penggorengan 50 detik dengan suhu $200^{\circ} \mathrm{C}$.

2. Pasir yang ideal untuk mengoreng kerupuk pada suhu $200^{\circ} \mathrm{c}$ dengan diameter $1-2 \mathrm{~mm}$

3. Suhu ideal untuk penggorengan kerupuk pasir minimal $170{ }^{\circ} \mathrm{c}$ dengan waktu penggorengan sedikit lama mencapai 80 detik.

4. Suhu maximal untuk penggorengan menggunakan alat penggoreng kerupuk pasir dengan screw dilengkapi pembalik putaran adalah $\pm 230{ }^{\circ} \mathrm{C}$

\section{Saran}

Saran untuk perbaikan alat penggoreng kerupuk pasir ini dipasang electronic control module yang menggontrol durasi waktu putaran motor serta temperature drum penggoreng dan aliran gas kompor agar suhunya stabil saat proses penggorengan yang bisa ditentukan sendiri suhunyasesuai jenis kerupuk yang akan digoreng agar tidak membuat kerupuk gosong atau masih mentah.

\section{DAFTAR PUSTAKA}

Afifah, Y. N. (2016). ALIRAN TAK TUNAK FLUIDA NANO MAGNETOHIDRODINAMIK ( MHD ) YANG MELEWATI BOLA.

Afifah, Y. N. (2019). (2019). Analysis of Unsteady Magneto Hydro Dynamic ( MHD ) Nano Fluid Flow Past A Sliced Sphere Analysis of Unsteady Magneto Hydro Dynamic ( MHD ) Nano Fluid Flow Past A Sliced Sphere. IOP Conference Series: Materials Science and Engineering, $\quad 494, \quad 012033$. https://doi.org/10.1088/1757899X/494/1/012033

Afifah, Y. N., \& Putra, B. C. (2018). Model Matematika Aliran Tak Tunak Pada Nano Fluid Melewati Bola Teriris Dengan Pengaruh Medan Magnet. Teknika: Engineering and Sains Journal, 2(2), 119-124.

Gunawan, E. et al. (2019) 'Analysis of the Effect of Current Flow Variations in GTAW on SS 400 Plate Material Connected with SUS 304 Stainless Steel Plate Against Tensile Strength and Hardness with ER308L Electrodes', Journal of Physics: Conference Series, 1175(1). doi: 10.1088/1742-6596/1175/1/012277.

Mesin, D. T., Teknik, F., Surabaya, U. N., Mesin, J. T., Teknik, F., \& Surabaya, U. N. (2015). ANALISA DAYA SEBAGAI PENGGERAK PADA MESIN PENGGORENG KERUPUK PASIR SEMIOTOMATIS DILENGKAPI PENGATUR SUHU Agung Prijo Budijono Abstrak Gambar 3. Rancangan Penelitian. 02, 58-63.

Nirwana, L. (2017). Lina Nirwana, Et al / Jurnal Pendidikan Teknologi Pertanian, Vol. 3 (2017) : S182-S196 S182. 3, 182-196.

Pendidikan, J., \& Pertanian, T. (2017). Jumriani $K$, Et al / Jurnal Pendidikan Teknologi Pertanian, Vol. 3 (2017) : S19-S29 S19. 3, 19-29.

Rantawi, A. basyir. (2006). Perancangan Unit Transfer (Screw Conveyor) Pada Mesin Pengisi Polibag Untuk Meningkatkan Efektivitas Kinerja Di Bidang Pembibitan. Motivation and Emotion, 30(3), 243-250.

Sularso. (2004). Dasar Perencanaan dan Penelitian. $1-374$.

Yunita Nur Afifah, MNH Qomarudin, \& Imamatul Ummah. (2020). Optimal Control Model Pemanenan Prey-Predator di Area Konservasi Ikan. Buana Matematika: Jurnal Ilmiah Matematika Dan Pendidikan Matematika, 10(1), $\quad 1-16$. https://doi.org/10.36456/buanamatematika. v10i1.2410 
I Umarella / Mechonversio, Vol. 2, No.1, Juni 2019, 33-38

Halaman ini sengaja dikosongkan 